\title{
Multi-sensor satellite and in situ measurements of a warm core ocean eddy south of the Brazil-Malvinas Confluence region
}

\author{
Ronald Buss de Souza ${ }^{\text {a,*}}$, Maurício M. Mata ${ }^{\mathrm{b}}$, Carlos A.E. Garcia ${ }^{\mathrm{b}}$, Milton Kampel ${ }^{\mathrm{a}}$, \\ Eduardo N. Oliveira ${ }^{a}$, João A. Lorenzzetti ${ }^{a}$ \\ ${ }^{a}$ Remote Sensing Division, National Institute for Space Research (INPE), São José dos Campos, SP, Brazil \\ b Department of Physics, Fundação Universidade Federal do Rio Grande (FURG), Rio Grande, RS, Brazil
}

Received 31 May 2005; received in revised form 21 September 2005; accepted 24 September 2005

\begin{abstract}
A warm core eddy was detected south of the Brazil-Malvinas (Falkland) Confluence (BMC) region in satellite images of the southwestern Atlantic Ocean in late 2002. The structure was also sampled by in situ instruments deployed by a ship in 2 days of November 2002 . An analysis of satellite data was performed to account for the lifecycle, dimension, surface temperature, surface chlorophyll concentration, surface height anomaly and displacement of the eddy since it was detached from the Brazil Current in September 2002. Satellite data were derived from several sources such as the AMSR-E, MODIS and radar altimeter. The structure lasted 64 days at south of the Brazil-Malvinas Confluence region later being re-assimilated by the Brazil Current return flow. In situ data collected during 2 days showed that the eddy was about $150 \mathrm{~m}$ deep, $5.5{ }^{\circ} \mathrm{C}$ warmer and 1 practical salinity unit saltier than adjacent waters. The salt anomaly associated to the eddy was estimated as $1.37 \times 10^{12} \mathrm{~kg}$ while its heat content was $4.24 \times 10^{18} \mathrm{~J}$. These are typical estimates for eddies present at the BMC region. Sea surface temperature (SST), chlorophyll concentration, and sea surface height anomaly time series were analyzed for the eddy's center along its trajectory path throughout its lifetime. Mean translational velocities for the eddy during its lifetime were computed from visual interpretation and by using an adaptation of the Maximum Cross-Correlation (MCC) method on AMSR-E SST images. The overall deviation between the two methods was $26 \%$. This suggests that the MCC method has a potential to be applied in monitoring programs to automatically account for the translational velocities of eddies in the BMC region.
\end{abstract}

(C) 2005 Elsevier Inc. All rights reserved.

Keywords: Warm core eddy; Eddy activity; Brazil-Malvinas Confluence; Mesoscale activity; Southwestern Atlantic Ocean; Multi-sensor observations

\section{Introduction}

The Brazil-Malvinas (Falkland) Confluence (BMC) region (Fig. 1) is one of the most dynamically active regions in the World Ocean (Chelton et al., 1990). In this region, the Brazil Current (BC) meets the Malvinas (Falkland) Current (MC) generating strong thermal gradients that are highly variable both in time and space (Legeckis \& Gordon, 1982; Olson et al., 1988; Podestá, 1997; Reid et al., 1977; Souza \& Robinson, 2004). The instabilities caused by the interaction between the warm waters from the $\mathrm{BC}$ with the cold waters from the $\mathrm{MC}$ at the surface result in very distinct mesoscale features such as meanders and eddies (Legeckis \& Gordon, 1982; Lentini et al.,

\footnotetext{
* Corresponding author.

E-mail address: ronald@dsr.inpe.br (R.B. de Souza).
}

2002). These features, together with the mesoscale instabilities of the $\mathrm{BC}$ and $\mathrm{MC}$, dominate the dynamics of the $\mathrm{BMC}$ region (Garzoli \& Simionato, 1990).

$\mathrm{Fu}$ (1996), for instance, presented results from the first 18 months of the TOPEX/Poseidon mission reporting that the most energetic variabilities of ocean the occur at the mesoscales $(\sim 100 \mathrm{~km}$ and 100 days $)$ and are related to mesoscale eddies. The strongest variabilities of the World Ocean at both annual and semiannual scales are found in the Agulhas Retroflection and BMC regions where the dynamic topography of the ocean presents amplitudes greater than 10 $\mathrm{cm}$. Provost and Le Traon (1993) also studied the altimetric variability of the BMC concluding that the region is highly inhomogeneous and anisotropic at the mesoscale. The inhomogeneity is very high at the $\mathrm{BC} / \mathrm{MC}$ front with typical amplitudes of $30 \mathrm{~cm}$ for the sea level and $1700 \mathrm{~cm}^{2} \mathrm{~s}^{-2}$ for the 


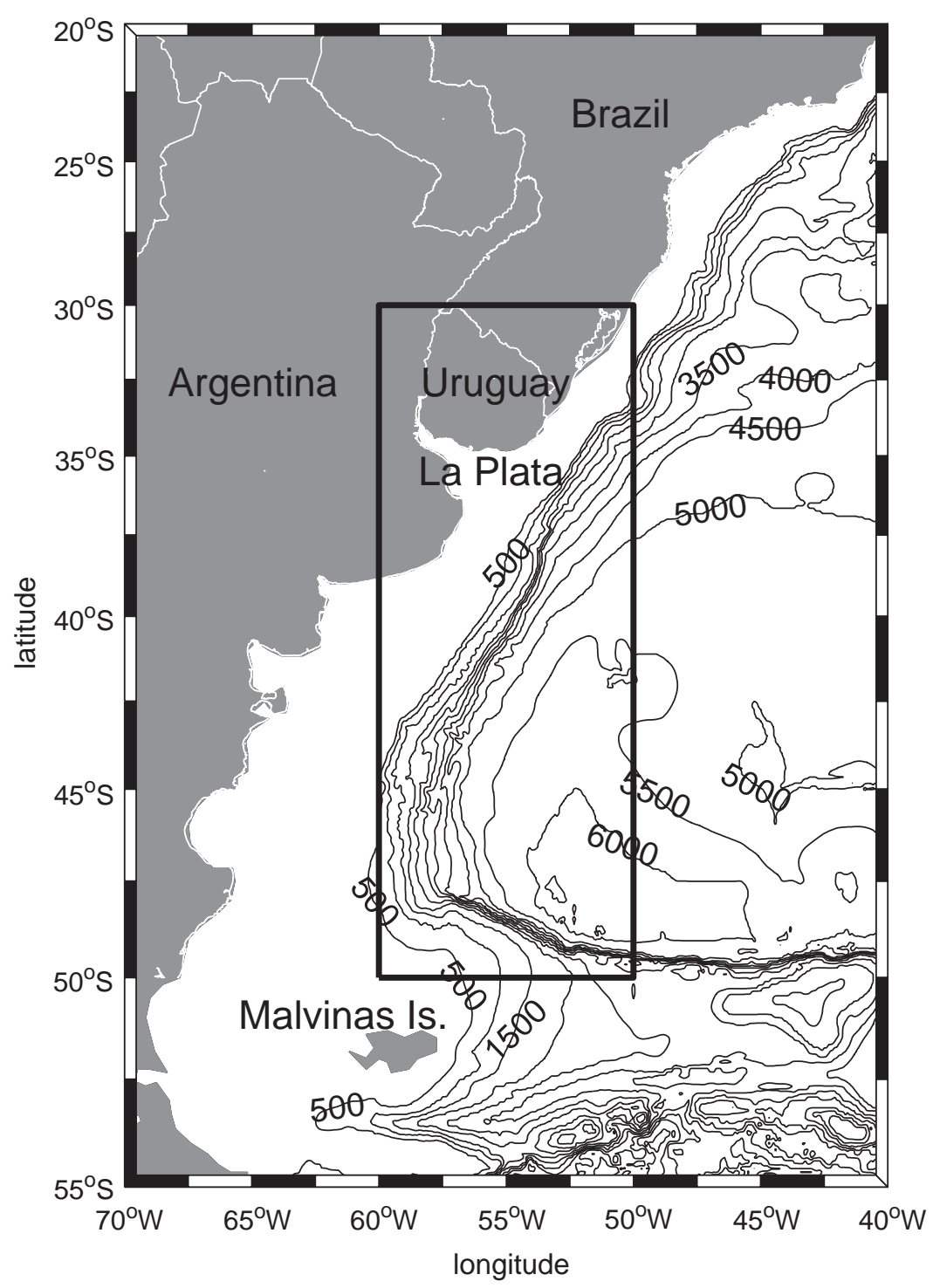

Fig. 1. Southwestern Atlantic Ocean and study area at the Brazil-Malvinas Confluence region (black rectangle) with bathymetry (m).

eddy kinetic energy. Low amplitudes are found in the MC (less than $8 \mathrm{~cm}$ and $150 \mathrm{~cm}^{2} \mathrm{~s}^{-2}$ ). The $\mathrm{BC}$ presents intermediate variability with typical amplitudes of $16 \mathrm{~cm}, 800 \mathrm{~cm}^{2} \mathrm{~s}^{-2}$.

The amplitudes of the annual cycle of the sea surface temperature (SST) fields at the BMC region are higher towards the continental shelf (Podestá et al., 1991). Minimum values of $8^{\circ} \mathrm{C}$ occur in June (Austral winter) while maximum SST can reach $25{ }^{\circ} \mathrm{C}$ in the summer at the core of BC (Goni et al., 1996). Lentini et al. (2000) estimated SST annual amplitudes ranging between $4{ }^{\circ} \mathrm{C}$ and $13{ }^{\circ} \mathrm{C}$ along the shelf at the western South Atlantic Ocean. The authors report that most of this variation is due to the increase of the $\mathrm{BC}(\mathrm{MC})$ transport during summer (winter) which contributed for the large SST amplitudes found off the La Plata river.

Maamaatuaiahutapu et al. (1999) have described the water masses present in the BMC region. On the surface in the BMC region, the $\mathrm{BC}$ is reported to transport the South Atlantic Central Water $(\mathrm{SACW})$ towards the south whereas the MC transports Sub-Antarctic Surface Water (SASW) in the opposite direction. The interaction between these two water masses produces mode waters known as Subtropical Mode Water (STMW) and Sub-Antarctic Mode Water (SAMW).

Owing to the extreme thermal and sea height contrasts present between the distinct water masses at the surface in the $\mathrm{BMC}$ region, this area has been frequently studied using satellite remote sensing techniques. Most of this research has focused on using visible and infrared radiometry from the Advanced Very High Resolution Radiometer (AVHRR), the Sea-viewing Wide Field-of-view Sensor (SeaWiFS) as well as altimeter data from various sensors (e.g. Chelton et al., 1990; Garcia et al., 2004; Legeckis \& Gordon, 1982; Olson et al., 1988). A recurring object of study is the mesoscale activity on the surface layers in the BMC region.

In a recent study using SeaWiFS and altimetry data for instance, Garcia et al. (2004) point out that BMC eddies are often generated by retroflection processes associated with 
current reversals, rather than by a classically known process such as meandering derived from zonal instabilities along the main current path (e.g. Gulf Stream or the Kuroshio). The coastline orientation in South America plays an important role in producing retroflection-generated eddies in the $\mathrm{BMC}$ region (Garcia et al., 2004; Silveira et al., 1999).

A mechanism of interaction of the $\mathrm{BC} / \mathrm{MC}$ front with westward propagating Rossby waves has been suggested by Garcia et al. (2004). Although not necessarily measuring the Rossby waves along the BMC region, Garcia et al. (2004) report that the eddy field structure present in the region is similar to that of the East Australian Current (EAC). The EAC poleward propagation is reported to be associated with Rossby waves traveling along the Tasman front. Extreme advances of the current towards the south are associated with strong meander formation and subsequent warm core eddy shedding from the EAC. The process also causes a contraction of the first cold meander (adjacent to the east of the warm meander) which, on the other hand, sheds a cold core eddy towards the north. This process is also observed in the BMC region.

Lentini et al. (2002) used 6 years of AVHRR 5-day SST composites to describe BC (warm core) eddies from January 1993 to December 1998. These eddies are known as effective mechanisms for the heat and salt exchange across the BC/MC front. Cold core eddies, as described by Souza and Robinson (2004) and Garcia et al. (2004) transport nutrients from the MC (eutrophic) towards the $\mathrm{BC}$ (oligotrophic) part of the $\mathrm{BC} / \mathrm{MC}$ front. The importance of $\mathrm{BC}$ eddies has also been acknowledged by Olson (1991) who reports that the energy stored by them is similar to that of eddies generated in more energetic currents such as the Gulf Stream. Lentini et al. (2002) report that warm core eddies are probably shed from the $\mathrm{BC}$ at a rate of 7 per year, maybe more. Although the authors report that these eddies have a tendency to be shed in the Austral spring to summer months (when the BC retroflection achieves its southernmost position), they acknowledge that during the Austral fall and winter months eddy detection from AVHRR images is hampered by the intense cloud coverage of the BMC region.

New passive microwave instruments such as the Tropical Rainfall Measuring Mission (TRMM), Microwave Imager (TMI) and the Advanced Microwave Scanning Radiometer for the Earth Observing System-EOS (AMSR-E) have been designed to provide SST estimates under all atmospheric conditions except rain (Wentz \& Meissner, 2000). Unlike TRMM which was launched into an equatorial orbit $\left(35^{\circ} \mathrm{N}\right.$ to $35^{\circ} \mathrm{S}$ ), the Aqua satellite has a polar orbit which provides global coverage for the AMSR-E sensor. The main limitation of all passive microwave instruments, however, is the poor spatial resolution $(\sim 25 \mathrm{~km})$ compared to the AVHRR or the Moderate-Resolution Imaging Spectroradiometer (MODIS; $\sim 1$ $\mathrm{km}$ ) visible and infrared sensors. Although the microwave SST data can be obtained on a more regular basis over cloudy areas such as the BMC region, AMSR-E SST data have not yet been used to study oceanographic conditions for this region.

By using a series of AMSR-E SST images together with other satellite data from MODIS and altimeters from the Jason-
1 and the European Remote Sensing-2 (ERS-2) satellites, this paper presents an analysis of the lifecycle, size variations, translational velocities and displacement of a singular eddy originating from the BC return flow in September 2002 in the BMC region. Time series of SST, surface chlorophyll- $a$ concentration (SCC) and sea level anomalies (SLA) inside the eddy were also analyzed for the period of its existence. Considering that the translation of eddies is an important mechanism of across-front mixing of properties in the ocean (Lentini et al., 2000; Richards \& Gould, 1996), it is important to develop an effective method for eddy tracking in areas of oceanographic fronts. Knowing that the use of visible and infrared data has always been a problem owing to persistent cloud cover in the BMC region, this paper also suggests that an application of the Maximum Cross-Correlation (MCC) method (Emery et al., 1986) can be used to automatically account for eddy translation in the BMC. The method, when applied to cloud-free, 1-day sequences of AMSR-E images, can be used in future eddy monitoring programs in the BMC region. Eddy properties such as volume, salt anomaly, heat content and available potential energy were estimated based on in situ and satellite measurements. In situ data taken inside the eddy during 2 days were also used to describe the structure's water mass composition.

\section{Data and data processing}

\subsection{MODIS imagery and eddy location}

During November 2002, a warm core eddy (ED1 hereafter) originating from the $\mathrm{BC}$ was observed from MODIS imagery of the BMC region located near $44^{\circ} \mathrm{S}, 56^{\circ} \mathrm{W}$. MODIS weekly averaged images were obtained from NASA at http:// oceancolor.gsfc.nasa.gov/ with spatial resolution of $4 \mathrm{~km} \times 4$ $\mathrm{km}$. First, the information about ED1's position was passed to the Brazilian Navy to guide the research vessel, RV Ary Rongel, towards its location. Second, the weekly MODIS images were processed for the BMC region from 6 September 2002 to 18 December 2002 comprising the time related to ED1's life span (see Section 3.1). Twelve weekly SCC maps were generated using the standard chlor_a2 (OC3M) algorithm from NASA (O’Reilly et al., 2000). Simultaneous weekly SST maps from MODIS data were also generated using the standard MODIS $11 \mu \mathrm{m}$ Non Linear Sea Surface Temperature Algorithm with coefficients derived by the University of Miami using as a first guess the Reynolds Optimum Interpolated SSTs (OISSTs). Given the persistent cloud cover of the BMC region during the period of this study, daily images from MODIS proved not to be very useful. For a comprehensive temporal analysis of SST data, therefore, we also used available cloudfree AMSR-E daily composites (see Section 2.3).

Despite the region being very cloudy during the period of this study, some daily MODIS SST and SCC images were useful for identifying ED1; indicating that its structure was very well developed and that it had detached from the BC by mid-November 2002. Fig. 2 presents two synoptic MODIS images (SST and SCC) simultaneously taken in 18 November 

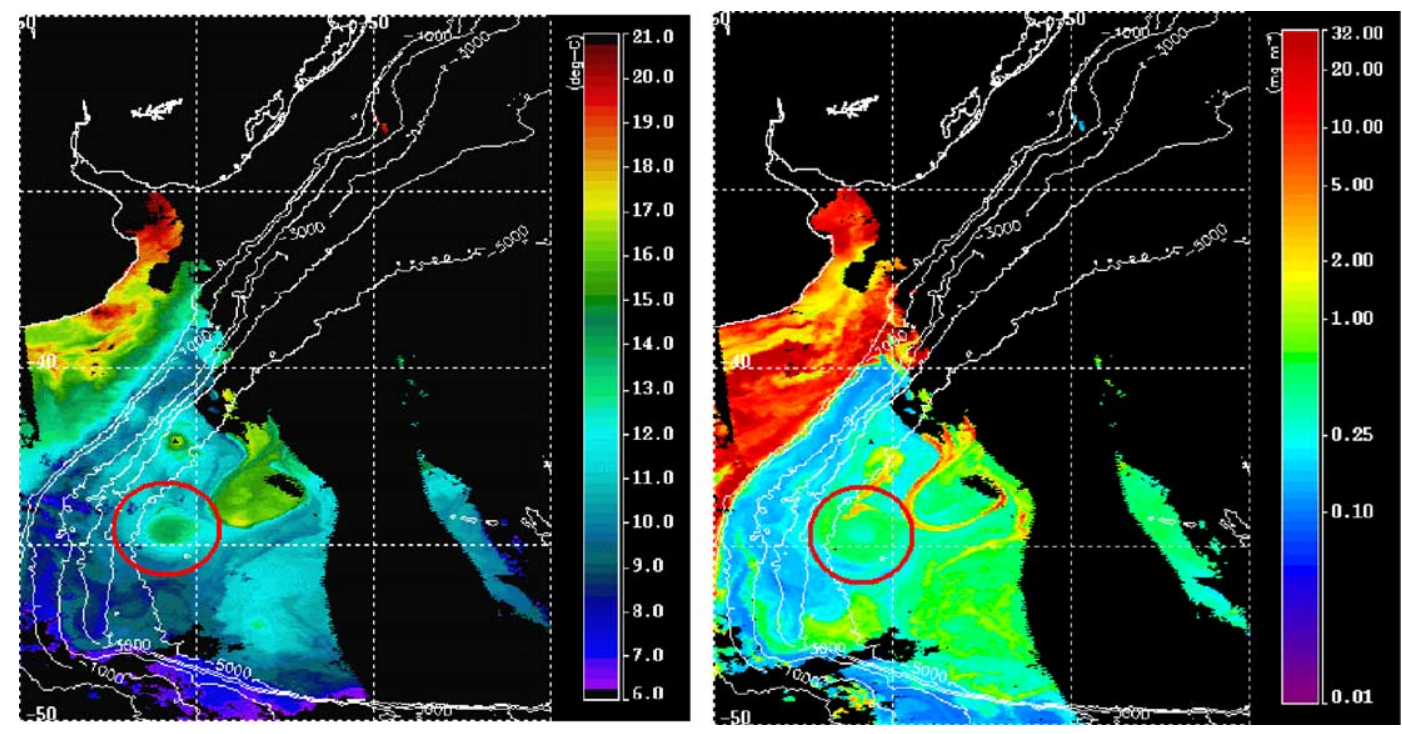

Fig. 2. MODIS SST $\left({ }^{\circ} \mathrm{C}\right.$, left panel) and SCC $\left(\mathrm{mg} \mathrm{m}^{-3}\right.$, right panel) images of 18 November 2002. ED1 is indicated by the red circles. (For interpretation of the references to colour in this figure legend, the reader is referred to the web version of this article.)

2002 showing ED1 completely separated from the BC. The figure shows that ED1 is a fully developed eddy with characteristics of the $\mathrm{BC}$. The figure also suggests that the eddy has been shed from the $\mathrm{BC}$ at its retroflection zone, consistent with observations described by Garcia et al. (2004) for other eddies in the region. The size, geometry and location of ED1 are also in agreement with a classical BC eddy presented by Olson et al. (1988).

Fig. 3 displays zoomed areas of Fig. 2 showing the SST and SCC signatures of ED1 on the MODIS images and along a transect taken across the structure. SST and SCC signatures are very distinct from adjacent waters. ED1 describes a classical behavior of Southern Hemisphere warm core eddies where external walls are colder with higher SCC than the nucleus. If we take the classical balance of Coriolis, pressure gradient and centrifugal forces in a rotating anticyclonic vortex, and assuming that there is a vertical velocity shear where the higher velocities are in the top layer, there is a depression of the thermocline at the vortex center (Defant, 1961). The consequence is that, at the center of the vortex, the colder and richer waters of the lower water layers are pushed downward from the euphotic layer depth. This results in the decrease of biological productivity and chlorophyll concentration from the walls towards the vortex center seen in Fig. 3.

The 12 weekly averaged SCC MODIS images of 6 September 2002 to 18 December 2002 were digitally processed using NASA's SeaDAS (SeaWiFS Data Analysis System) software. Visual inspection of the enhanced MODIS images together with the AMSR-E imagery helped in isolating ED1 and determining the dates related to the shedding and
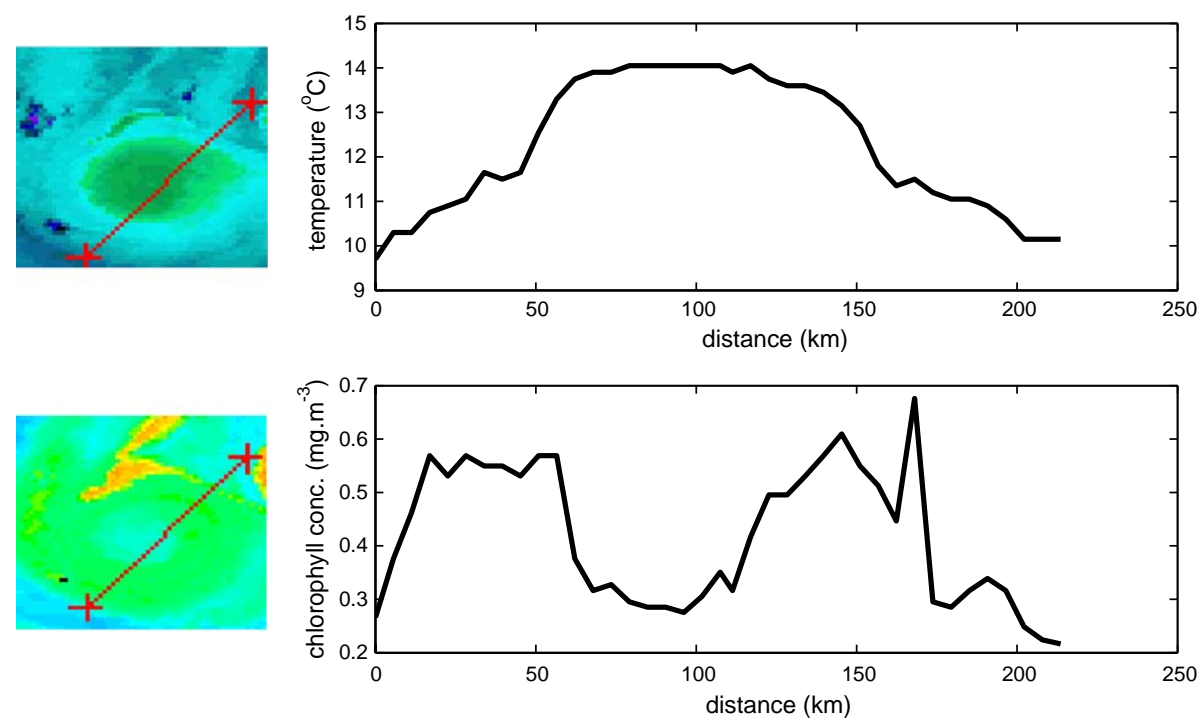

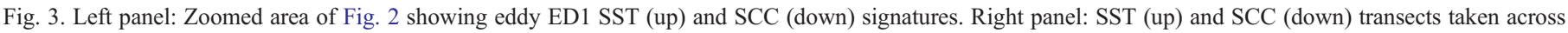

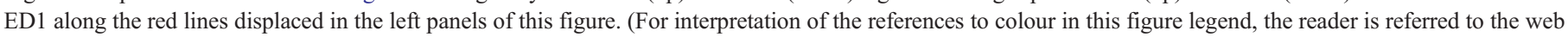
version of this article.) 
coalescence of the eddy. From the individual MODIS images, the SCC at the eddy center was calculated. This permitted the analysis of the temporal variation of chlorophyll concentration throughout the eddy's lifecycle.

\subsection{In situ data}

Based on initial satellite cueing data, the onboard thermosalinograph was used while at sea to accurately locate ED1. The structure was located by surface temperature and salinity $(T, S)$ anomalies with respect to adjacent waters. Although $T, S$ data were recorded continuously during the RV Ary Rongel's cruise to Antarctica, the data used here were restricted to latitudes between $40^{\circ}$ and $48^{\circ} \mathrm{S}$ (Fig. 4). The data was filtered using a simple, 32-point moving average filter which resulted in a time series with a temporal resolution of about $1 \mathrm{~h}$. These data were used to compute the density of the surface waters using the International Equation of State, 1980 (IES $80-$ Millero \& Poisson, 1981).

On 13-14 November 2002, while the ship was traveling in the vicinity and inside the eddy, four Expendable Bathythermograph (XBT) probes were launched at ED1 - one on the northern eddy wall, one on the southern end, and two in the ED1 center (Fig. 4). Another XBT was launched on 17 November 2002 at a site further south of our study area. Details about the XBT launching positions are described in Table 1.

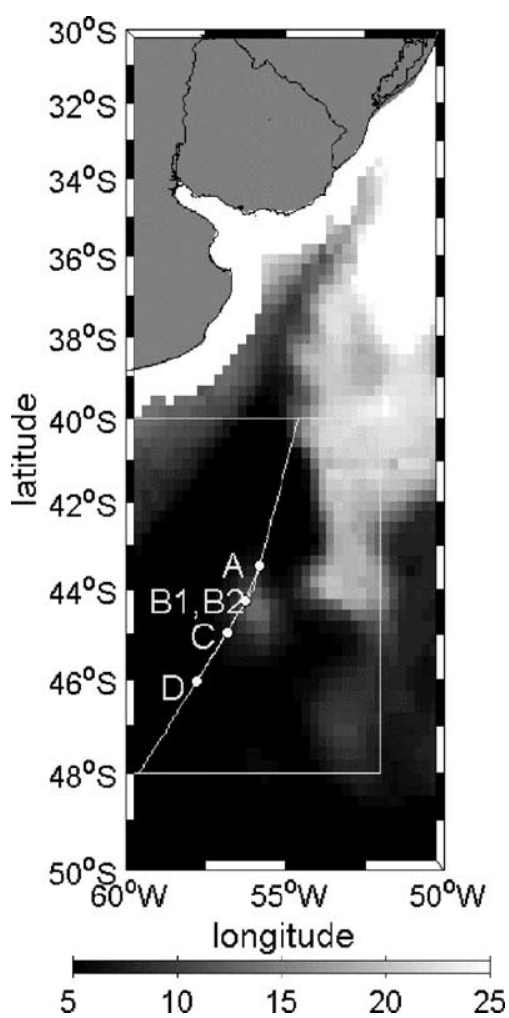

Fig. 4. AMSR-E SST $\left({ }^{\circ} \mathrm{C}\right)$ image of 13 November 2002 showing eddy ED 1 near $44^{\circ} \mathrm{S}, 56^{\circ} \mathrm{W}$ at the Brazil-Malvinas Confluence region. Ship track and the XBT launching positions (white circles) are included. The white rectangle is the area of Fig. 7.
Table 1

XBT launching positions at the vicinity and inside eddy ED1

\begin{tabular}{llllll}
\hline XBT no. & $\begin{array}{l}\text { Launching } \\
\text { date in 2002 }\end{array}$ & $\begin{array}{l}\text { Launching } \\
\text { time }(\mathrm{GMT})\end{array}$ & $\begin{array}{l}\text { Latitude } \\
\left({ }^{\circ} \mathrm{S}\right)\end{array}$ & $\begin{array}{l}\text { Longitude } \\
\left({ }^{\circ} \mathrm{W}\right)\end{array}$ & $\begin{array}{l}\text { Location in } \\
\text { relation to ED1 }\end{array}$ \\
\hline $\mathrm{A}$ & $13 \mathrm{Nov}$ & $16: 25$ & 43.475 & 55.81 & Northern wall \\
$\mathrm{B} 1$ & $13 \mathrm{Nov}$ & $22: 02$ & 44.267 & 56.225 & Center \\
$\mathrm{B} 2$ & $13 \mathrm{Nov}$ & $22: 09$ & 44.267 & 56.225 & Center \\
$\mathrm{C}$ & $14 \mathrm{Nov}$ & $02: 05$ & 44.967 & 56.833 & Southern wall \\
$\mathrm{D}$ & $17 \mathrm{Nov}$ & $00: 01$ & 46.05 & 57.78 & STMW \\
\hline
\end{tabular}

\subsection{AMSR-E images}

AMSR-E is an eight-channel dual polarization (except for the $50 \mathrm{GHz}$ channels) passive microwave radiometer operating at $6.925 \mathrm{GHz}, 10.65 \mathrm{GHz}, 18.7 \mathrm{GHz}, 23.8 \mathrm{GHz}, 36.5 \mathrm{GHz}$, $50.3 \mathrm{GHz}, 52.8 \mathrm{GHz}$ and $89 \mathrm{GHz}$. AMSR-E is a modified version of AMSR that flew on the Advanced Earth Observing Satellite-II (ADEOS-II). The AMSR-E sensor flies since 2002 when the satellite Aqua was put into a polar orbit on the EOS mission. AMSR does not fly on the Terra satellite. Although similar to the TMI instrument, AMSR-E has the advantage of covering the entire globe whereas TMI only covers the tropics. This is extremely important for the BMC region which, from 2002 onwards, can now be covered in all atmospheric conditions except heavy rain.

All stages of processing from raw AMSR-E channels data into SST are performed at Remote Sensing Systems (RSS) in Santa Rosa, California. SST is computed at an accuracy of 0.5 $\mathrm{K}$ owing to its strong relationship with the sea surface brightness temperatures (TBs) measured by the AMSR instrument at its different (frequency and polarization) channels. TBs are used as input parameters in a radiative transfer model which computes SST by a multiple-linear regression method (Wentz \& Meissner, 2000; Wentz et al., 2003). Final SST products take NCEP (National Center for Environmental Prediction) wind directions in order to retrieve more accurate SSTs as well as microwave wind speeds. Data files are usually complete within 2 days of observation. Preliminary validation of the AMSR-E SST was performed by Wentz et al. (2003) against weekly OISSTs. The RMS difference between AMSR$\mathrm{E}$ and OISSTs was $0.76{ }^{\circ} \mathrm{C}$ over a 3-month period spanning from June to August 2002. Although the OISSTs are constructed by merging global satellite (AVHRR) estimates with in situ data (Reynolds \& Smith, 1994), to date no attempt has been made to directly compare AMSR-E with AVHRR data sets. Although the validation of the AMSR-E images are important for an accurate determination of the global SST fields provided by this sensor, this determination is not the objective of this paper. Rather, the determination of the SST gradients for feature (eddy) localization and tracking is more important here. Having said that, we believe the AMSR-E images are accurate enough for the objectives of this paper.

For the present work, 3-day AMSR-E global composites representing daily SST data were obtained from June to December 2002 from the RSS ftp site. Using the AMSR-E plus the MODIS images we determined that ED1 existed for 64 days (64 AMSR-E SST images) spanning from 21 September 
to 24 November 2002. ED1 was isolated at each AMSR-E image. We also determined its dimensions and assessed its SST data for a time series analysis. Typically, ED1 was identified as a closed (warm) ellipse with the borders delimited by maximum horizontal thermal gradients in relation to adjacent (cold) waters (Fig. 4). In agreement with Souza (2000) and Souza and Robinson (2004), thermal gradients between the warm and cold waters of the BMC region were typically found to be about $0.1{ }^{\circ} \mathrm{C} \mathrm{km}^{-1}$. After the identification of the eddy, central SSTs were recorded for each day during its lifecycle. Displacement and translational velocities were computed manually from the temporal variation of ED1's center position.

\subsection{Altimetry data}

The altimetry data used in this study were collected by the Jason-1 and ERS-2 satellites. The data from the different satellites have been merged to form Maps of Sea Level Anomalies (MSLA) with respect to the long-term mean sea level. The processing and validation of the data set was performed by the AVISO Project (Archive, Validation et Interpretation des donnes des Satellite Oceanographiques), the oceanographic satellite databank of the French space agency CNES (Centre National d'Etudes Spatiales). The processing of altimeter data starts with quality control and validation followed by geophysical corrections. Altimeter measurements from all satellites require correction for instrumental errors, atmospheric corrections (e.g. wet tropospheric, dry tropospheric and ionospheric effects), ocean wave influence (sea state bias), tides (ocean tide, earth tide and pole tide) and the inverse barometer effect. Ocean tides in particular can lead to large errors in some shallow areas. Details of the models used and how these environmental corrections were applied can be found in CLS (2004).

Ducet et al. (2000) assessed the improvements obtained by merging distinct altimetry data sets, especially for the study of ocean mesoscale phenomena (see also Hernandez et al., 1995; Le Traon \& Dibarboure, 1999; Le Traon et al., 2001). The authors concluded that the merged data set provides a more homogeneous data field with reduced mapping errors compared to individual data sets. This implies that more realistic sea level and geostrophic currents can be estimated. In the final stages of the along-track altimetry data processing, an estimate of the mean sea surface height ( $\mathrm{SSH})$ is removed from the data set, resulting in along-track sea level anomalies (SLA). This is done in order to remove contamination introduced in the data from high-frequency uncertainties due to estimating Marine Geoid undulations.

The MSLA data are obtained from the SLA using an improved space/time objective analysis method proposed by Le Traon et al. (1998). The method effectively interpolates data from the original satellite ground tracks onto a regular geographical grid. The MSLA are calculated every 7 days and have a horizontal resolution of $1 / 3^{\circ} \times 1 / 3^{\circ}$. Full details can be found in CLS (2004).

MSLA were produced for the months of September to December 2002 for the region of this study. Eddy ED1 could be fully identified in a temporal sequence of 8 MSLA maps spanning from 9 October to 27 November 2002. SLA values were recorded for the eddy's center on each map allowing the build-up of a time series throughout ED1's lifetime.

\subsection{Applying the Maximum Cross-Correlation Method to AMSR-E imagery}

In order to automatically compute the translational velocities of ED1, the Maximum Cross-Correlation (MCC) method was tested using the $25-\mathrm{km}$ pixel resolution AMSR-E imagery. The objective was to compare these velocities to the ones computed manually from the visual interpretation analysis. A good performance of the method compared to manual computations would save processing time and allow an easy, straightforward, semi-automatic method for eddy tracking in the BMC region based on any newly available (albeit lowresolution) cloud-free data.

The application of the MCC method on AMSR-E images demanded some adaptations. Previous oceanographic applications of the method at the BMC region were based on 1-day sequences of high-resolution visible or infrared images (e.g. Domingues et al., 2000). Many authors (e.g. Lentini et al., 2002; Olson et al., 1988; Souza, 2000), however, have already stated that cloud contamination is a crucial problem for consistent monitoring of the SST fields, currents and mesoscale structures such as eddies in the region. While the infrared images are very often cloud contaminated, the absence of clouds in the AMSR-E sequences offers us the advantage of using images for long periods of time in the BMC region.

The MCC technique is based on the maximum crosscorrelation coefficient between matrices of pixels covering the same region in sequential images (Emery et al., 1986). A template window is defined from the first image whose dimensions are a function of the study area. In the second image, a larger area is selected and defined as the search window. The central pixel location is the same in the two sequential images which, in our application, coincides with the ED1 center. This position was visually identified as the hottest pixel inside ED1. The maximum cross-correlation found from the displacement of the template window over the search window defines the velocity vector of the surface current. The cross correlation coefficient $(c)$ is obtained from Emery et al. (1986) as follows:

$c=\frac{1}{\sigma_{\mathbf{A}} \sigma_{\mathbf{B}}} \Sigma \Sigma\left\{\left(\mathbf{A}-\mathbf{A}_{\mathrm{m}}\right)\left(\mathbf{B}-\mathbf{B}_{\mathrm{m}}\right)\right\}$

where $\mathbf{A}$ is the template window matrix extracted from the first image of the pair, $\mathbf{B}$ is the matrix extracted from the displacement of the template window over the search window, $\mathbf{A}_{\mathrm{m}}$ and $\mathbf{B}_{\mathrm{m}}$ are mean values for each matrix, $\sigma_{\mathbf{A}}$ and $\sigma_{\mathbf{B}}$ are the standard deviations for $\mathbf{A}$ and $\mathbf{B}$ matrices.

The MCC method was applied to the AMSR-E images according to Table 1 . Thirteen image pairs were used with a time interval of 9 days between the pairs. Consecutive pairs, however, overlapped in time at a 5-day period. These time intervals were chosen after many tests (not shown) as a 
compromise between the AMRS-E images pixel size $(25 \mathrm{~km})$, translational velocities computed manually and the translational velocities of eddies expected for the study region from previous work. Lentini et al. (2002) reported BC rings moving at translational velocities ranging from $4.2 \mathrm{~km} \mathrm{day}^{-1}$ to 27.2 $\mathrm{km} \mathrm{day}{ }^{-1}$. For our study, the template and search windows were set at dimensions of $5 \times 5$ and $15 \times 15$ pixels, respectively. This configuration produces $21.6 \mathrm{~km}^{-1 a y}{ }^{-1}\left(\sim 25 \mathrm{~cm} \mathrm{~s}^{-1}\right)$ as the maximum possible velocity that can be computed.

Velocity fields were generated for each image pair of Table 2. The vectors indicate the translation of ED1 in the image sequences. Vectors not contained in a $6 \times 6$ pixel filtering window were eliminated. After that, the resulting vectors were filtered taking into account the correlation coefficients and the maximum velocity expected for the feature's translation in the study region. Only vectors computed from correlations higher than $80 \%$ associated with speeds slower than $21.6 \mathrm{~km}_{\text {day }}{ }^{-1}$ were maintained. Once the velocity vector field was assessed from the various image pairs, monthly means and associated standard deviations were computed to be compared with the results taken from the visual interpretation analysis.

\subsection{Volume, salt anomaly, heat content and available potential energy}

The computation of ED1 volume (Vol) was based upon the mean radius (rd) of ED1 taken from the satellite (AMSR-E) data and the depth $\left(H_{\text {eddy }}\right)$ of the structure, taken from the XBT data at its center. The volume of an eddy is a measure of the content of water carried by the structure from one environment to another. For simplification and comparison to other authors' results, the volume of ED1 was considered to be that of a cylinder:

$\mathrm{Vol}=\pi r^{2} H_{\text {eddy }}$

Where $r$ is half of the mean diameter computed from the average of the major and minor axes of ED1 taken from the visual interpretation of the AMSR-E images.

The salt anomaly in the context of this work is the salt content transported by ED1 from the $\mathrm{BC}$ domain towards the sub-Antarctic environment. The salt anomaly was computed to

Table 2

AMSR-E image pairs for the MCC and date interval between the pairs

\begin{tabular}{llr}
\hline Pairs & Image date interval (day/month in 2002$)$ \\
\hline P1 & $21 / 09$ & $30 / 09$ \\
P2 & $30 / 09$ & $09 / 10$ \\
P3 & $05 / 10$ & $14 / 10$ \\
P4 & $09 / 10$ & $18 / 10$ \\
P5 & $14 / 10$ & $23 / 10$ \\
P6 & $18 / 10$ & $27 / 10$ \\
P7 & $23 / 10$ & $01 / 11$ \\
P8 & $27 / 10$ & $05 / 11$ \\
P9 & $01 / 11$ & $10 / 11$ \\
P10 & $05 / 11$ & $14 / 11$ \\
P11 & $10 / 11$ & $19 / 11$ \\
P12 & $14 / 11$ & $23 / 11$ \\
P13 & $19 / 11$ & $28 / 11$ \\
\hline
\end{tabular}

derive the amount of excess mass of salt inside ED1's volume after its shedding. From the thermosalinograph data, ED1 was found to be 1 practical salinity unit (PSU) saltier than adjacent waters. Each PSU equals $1 \mathrm{~g}$ of salt for each $1 \mathrm{~kg}$ of seawater.

The heat content $(\mathrm{Hc})$ of an eddy is a measure of the heat stored within this structure which can be transported by the eddy's translation to other regions where it can be dissipated into other water masses and to the lower atmosphere by oceanatmosphere exchange. For ED1, Hc was computed as:

$\mathrm{Hc}=\rho c_{\mathrm{p}} T \mathrm{Vol}$

where $\rho$ is the water density of $\mathrm{ED} 1, c_{\mathrm{p}}$ is the specific heat capacity of the water at the surface, $T$ is the mean temperature and $\mathrm{Vol}$ is the volume of the eddy.

Garzoli and Garraffo (1989) suggested that the available potential energy (APE) of an eddy can be estimated from hydrographic data. This energy is the part of the potential energy which can be actually converted into kinetic energy and gives an estimate of the intensity of an eddy. APE can be computed as follows:

$\mathrm{APE}=\rho g^{\prime} \int_{0}^{r_{\mathrm{m}}} 2 \pi r d r\left(H_{\mathrm{eddy}}-\mathrm{Ho}\right)^{2}$

or

$\mathrm{APE} \cong 2 \pi \rho g^{\prime} d r \sum r \Delta H^{2}$

where $r_{\mathrm{m}}$ is the mean eddy radius, $g^{\prime}=0.013 \mathrm{~m} \mathrm{~s}^{-}$super $^{2}$ is the reduced gravity found for the BMC region given by Garzoli and Garraffo (1989), and Ho is the depth of the mixed layer away from the ED1 influence area. From XBT data, Ho could be estimated as $20 \mathrm{~m}$ (station C, Fig. 9).

\section{Results and discussion}

\subsection{Eddy lifecycle examined by multi-sensor satellite data}

The surface signature of ED1 showed up well in weekly averaged MODIS SST and SCC images as well as in the daily AMSR-E data set. Fig. 5 presents a 12-week temporal sequence of MODIS SST images at the BMC region. The sequence covers the same 12-week time span described in Section 2.1. ED1's formation, translation and coalescence are easily noticed during the sequence. ED1 was also identified in the MODIS SSC weekly images (not shown), although the chlorophyll signal is weaker than the SST one.

The MODIS sequences were used to determine that ED1 had been ejected from the BC return flow in the week of beginning on 22 September 2002. Another eddy is seen close to the position of ED1 in the SST image of 14-21 September. This last structure is seen just southeast of ED1 in the week of 22-29 September. The images also suggest that ED1 was reassimilated into the $\mathrm{BC}$ return flow in the week of 25 November to 2 December 2002 (Fig. 5), although the image of 3-9 December presents a larger, zonally orientated eddy which was left after the interaction of ED1 with the BC and subsequent retraction of the last. This last eddy, for vorticity 


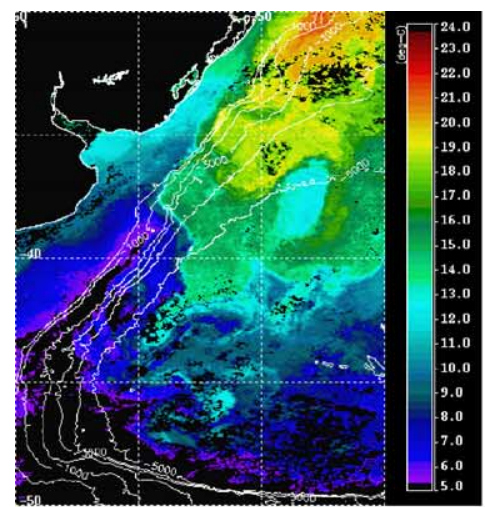

Sep 6 - Sep 13

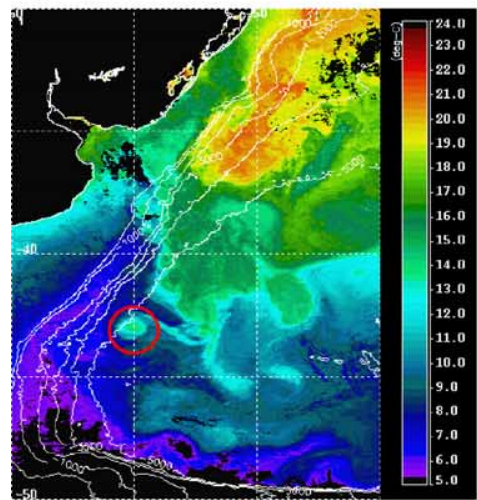

Sep 30 - Oct 6

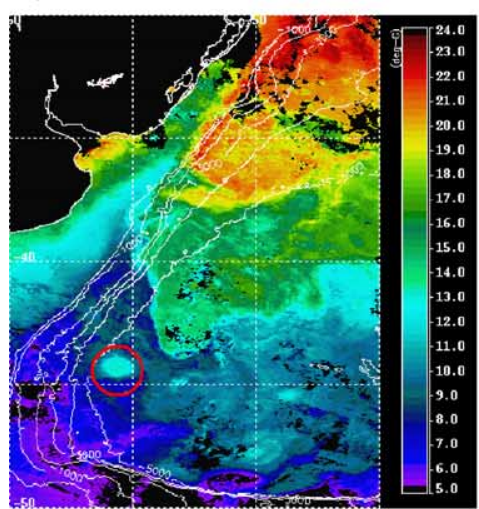

Oct 24 - Oct 31

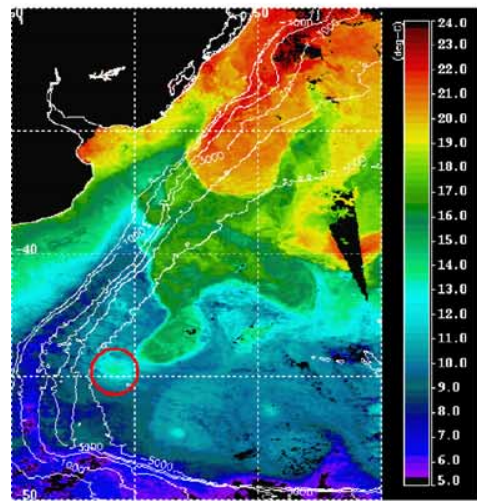

Nov 17 - Nov 24

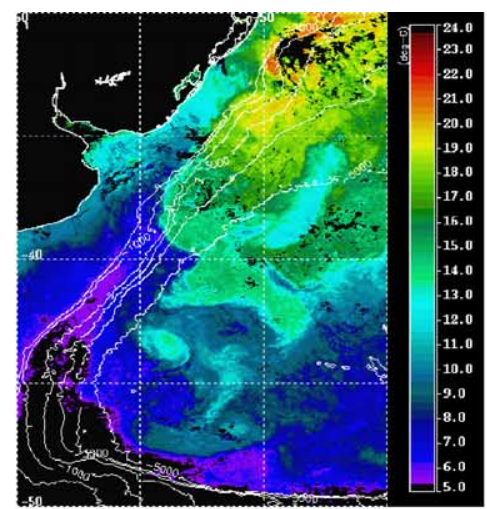

Sep 14 - Sep 21

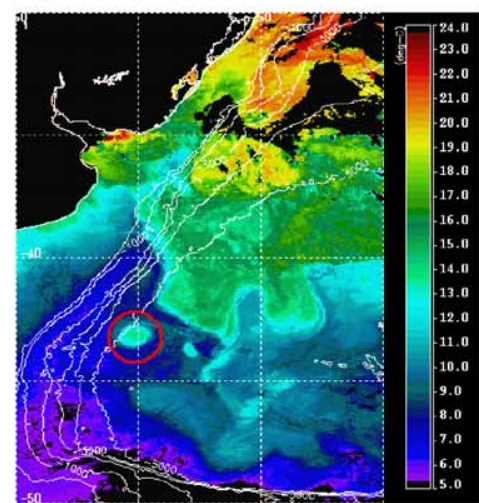

Oct 7 - Oct 15

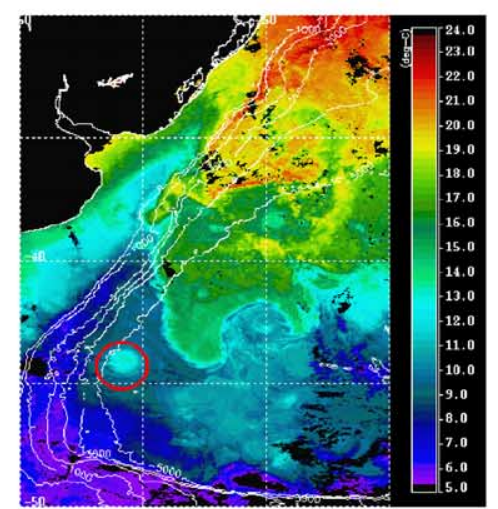

Nov 1 - Nov 8

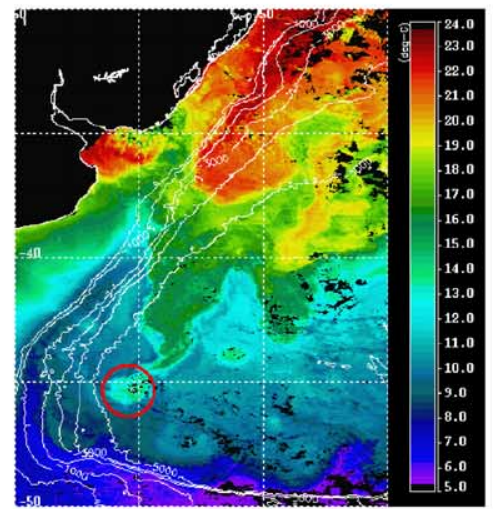

Nov $25-$ Dec 2

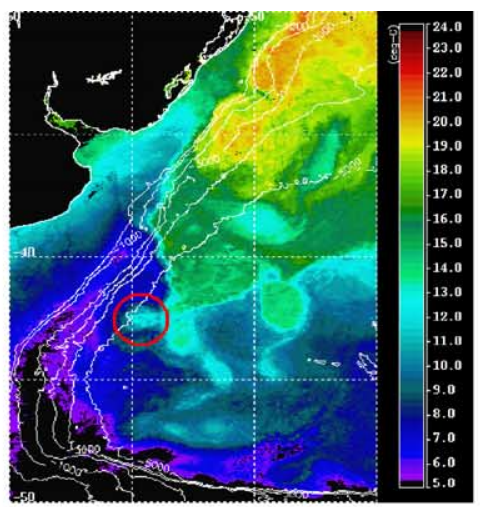

Sep 22 - Sep 29

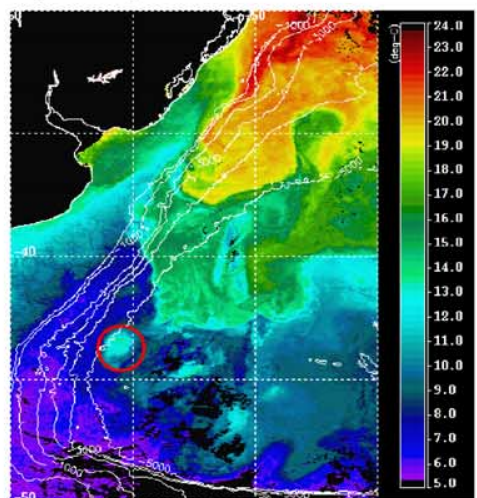

Oct 16 - Oct 23

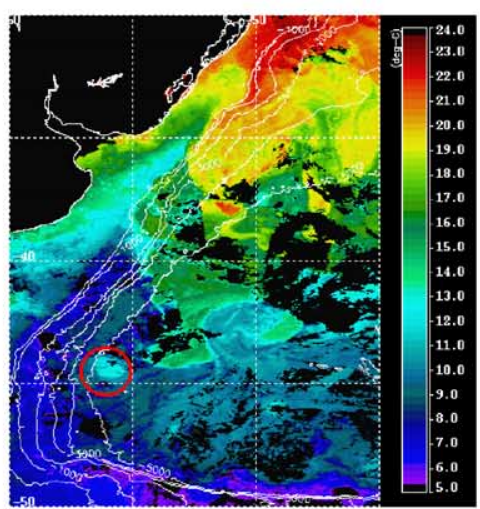

Nov 9 - Nov 16

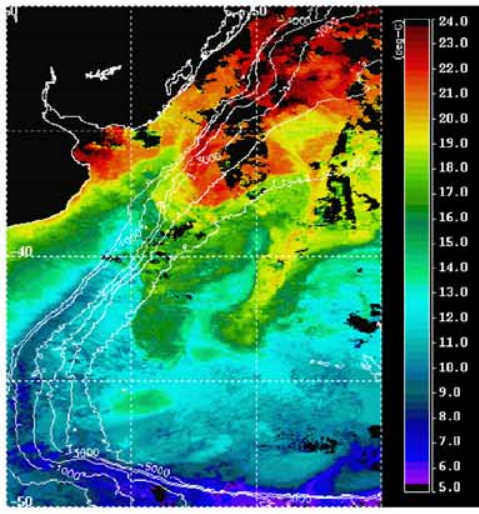

Dec 3 - Dec 10

Fig. 5. MODIS weekly averaged SST $\left({ }^{\circ} \mathrm{C}\right)$ sequence from 6 September to 10 December 2002 (top to bottom, left to right). ED1 is indicated by the red circles. (For interpretation of the references to colour in this figure legend, the reader is referred to the web version of this article.) 
restrictions, can not be ED1 as it was defined before interacting with the $\mathrm{BC}$ during the week before. Parallel analysis of the AMSR-E images corroborated the dates found from the MODIS sequences. Overall lifetime of ED1 spanned 64 days from 21 September to 24 November 2002. This time span is consistent with Lentini et al. (2002) who found BC eddies to last between 11 and 95 days.

The MSLA presented in Fig. 6 show that the SLA signature of ED1 was (as expected for warm core eddies) higher than its adjacent waters. At its center, ED1 had positive SLA as high as $0.6 \mathrm{~m}$. The sequence shows ED1 fully detached from the $\mathrm{BC}$ in 9 October 2002. As seen in the MODIS sequence (Fig. 5), the movement of ED1 towards re-assimilation by the BC is fully noticeable. Re-assimilation occurs in late November 2002. The eddy was not distinct from adjacent waters at periods before and after the period of 9 October to 27 November 2002 (not shown).

\subsection{Eddy translation and mean velocity field}

A temporal sequence of AMSR-E images was used to identify the moment ED1 pinched off the BC return flow. As previously described, visual analysis of multi-sensor satellite data has established 21 September 2002 as the date ED1 to have completely separated from the $\mathrm{BC}$ at the surface. Contrary to most eddies shed from the $\mathrm{BC}$ retroflection which are directed towards the south, ED1 was ejected towards the west. After completely shedding, ED1 takes a path already described for BC eddies in the region (Lentini et al., 2002).

Fig. 7 (left panel) was drawn from the visual interpretation of all 64 AMSR-E images where ED1 was isolated. The figure shows the progression of ED1 geometry and position during its lifetime. The translation of ED1 follows the known path of the $\mathrm{BC}$ return flow in the $\mathrm{BMC}$ region with directions varying from SW to SE.

The MCC velocity (filtered) fields are shown in Fig. 7 (right panel). Compared to visual interpretation, the MCC vectors presented a good performance in representing the overall velocity field while tracking ED1 after its complete formation. MCC vectors, in this case, were uniformly directed, easily characterizing a mean velocity. However, this was not the case when the MCC technique was applied to the first image pair (P1, Table 2). In this situation, the separation distance between ED1 and the BC was not large enough. For this reason, pair P1 estimates were excluded from the present analysis.
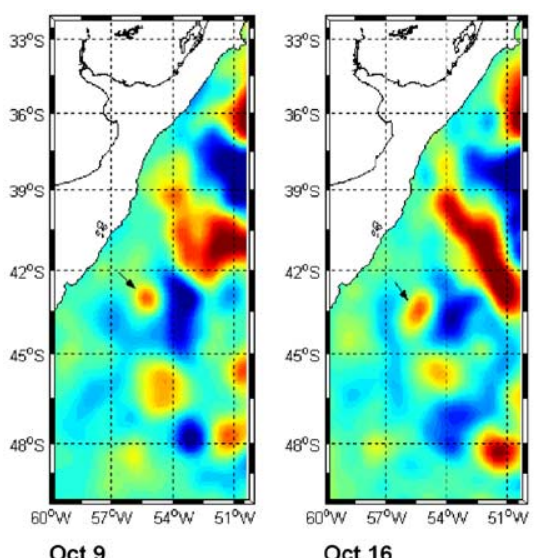

Oct 16

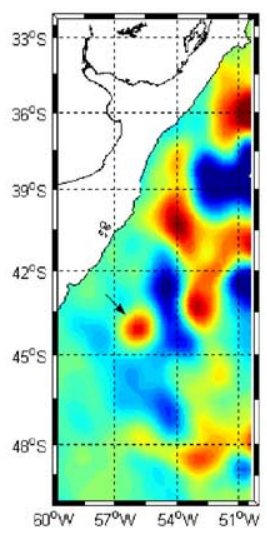

Nov 6

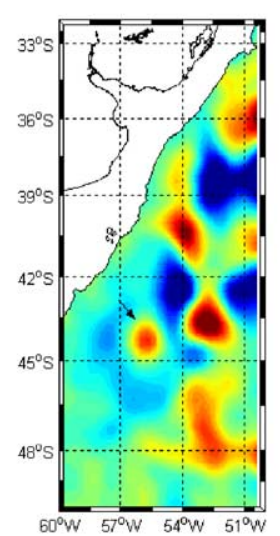

Nov 13

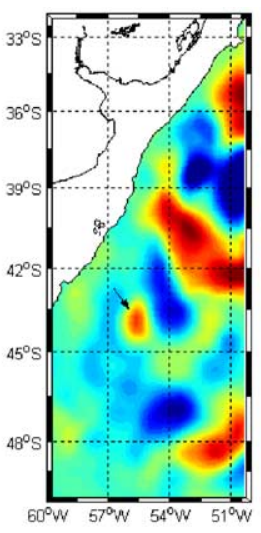

Oct 23

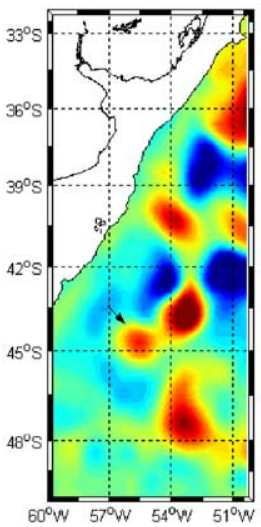

Nov 20

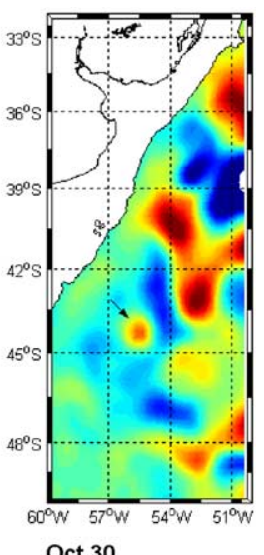

Oct 30

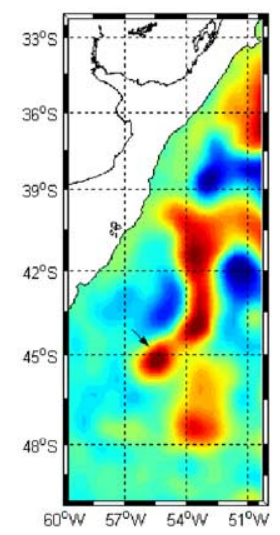

Nov 27

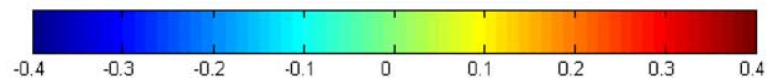

Fig. 6. SLA (m) weekly maps from 9 October to 27 November 2002 (top to bottom, left to right). ED1 is indicated by the arrows. 


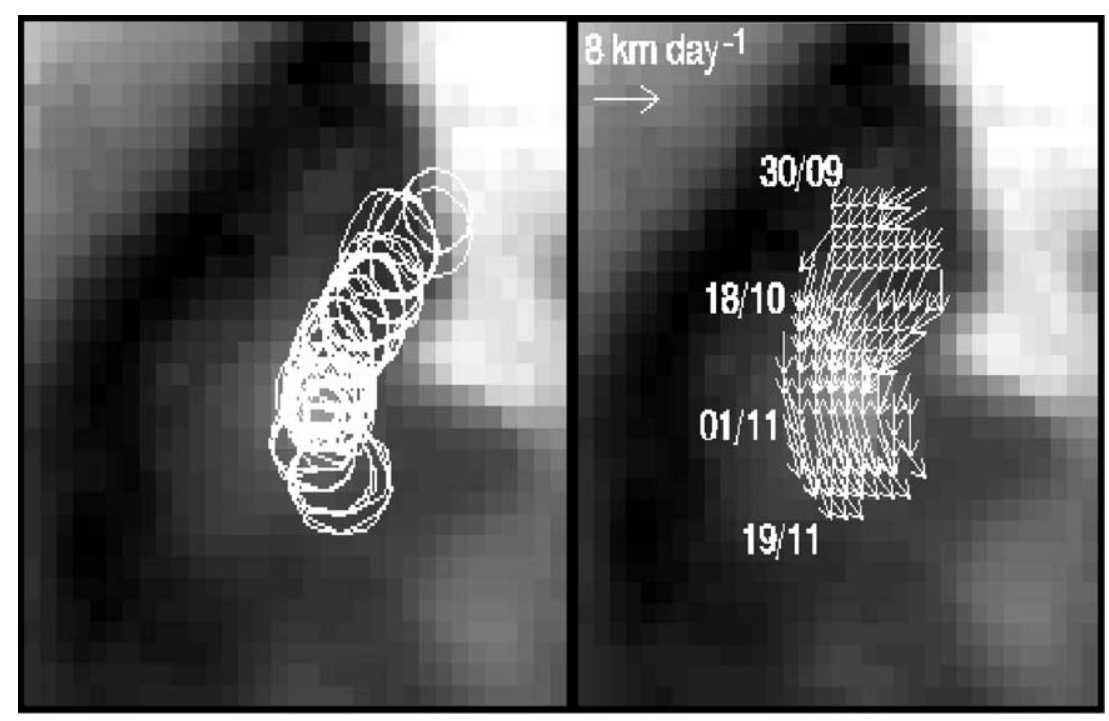

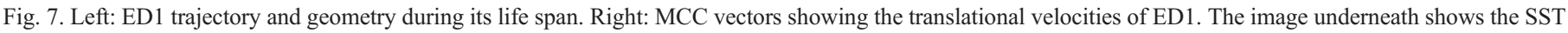
field on 13 November 2002 in the zoomed area of Fig. 4: dark tones represent the Malvinas Current; white tones represent the Brazil Current.

Monthly mean ED1 translational velocities computed both manually and using the MCC method, are displayed in Table 3. Overall, mean velocities computed from the two methods were $7.8 \mathrm{~km} \mathrm{day}^{-1}$ and $5.8 \mathrm{~km} \mathrm{day}{ }^{-1}$, respectively. Directions associated with these velocities were $248^{\circ}$ and $246^{\circ}$ (SW-S), respectively. Monthly velocities, except for September, are similar when computed by the two methods used here. In the months after September, differences varied between $0.4 \mathrm{~km}$ day $^{-1}$ and $2.3 \mathrm{~km} \mathrm{day}^{-1}$ (Table 3).

The overall difference between the two methods is $2 \mathrm{~km}$ day $^{-1}(26 \%)$. This is considered to be accurate given the spatial resolution of the AMSR-E images. The similarity between translational velocities computed from the two methods demonstrate the ability of the MCC method to estimate velocities accurately for individual eddies in the BMC region from AMSR-E image pairs, especially after these eddies have completely formed. The method's poor ability to isolate ED1 from its SST background field immediately after formation, however, can explain the large difference between MCC and visual interpretation velocities computed for September 2002 (Table 3).

The magnitudes of ED1 translational velocities are in agreement with Legeckis and Gordon (1982), who analyzed other eddies in the BMC region. These authors found velocities ranging from $4 \mathrm{~km} \mathrm{day}^{-1}$ to $35 \mathrm{~km}$ day $^{-1}$. Lentini et al. (2002) described $\mathrm{BC}$ warm core eddy translational velocities ranging from $4 \mathrm{~km} \mathrm{day}^{-1}$ to $27 \mathrm{~km} \mathrm{day}^{-1}$ (mean $=13.1 \mathrm{~km} \mathrm{day}^{-1}$ ).

\subsection{Eddy thermohaline characteristics}

Coincident with XBTs measurements, the thermosalinograph data indicated that SST inside the ED1 core was maximum at $13.2{ }^{\circ} \mathrm{C}$ (Fig. 8, top) during 13-14 November 2002. For comparison, we found that the AMSR-E SST at the center of the eddy on 13 November was $12.8^{\circ} \mathrm{C}$. The salinity inside the ED1 core reached a maximum of 35.2 at these dates. The in situ data showed that ED1 was about $5{ }^{\circ} \mathrm{C}$ warmer and 1 PSU saltier than its adjacent waters. A scatter diagram of the temperature and salinity data, known as a $T, S$ diagram (Fig. 8, bottom) was used to classify the water masses present in the study area in the same manner as Maamaatuaiahutapu et al. (1999). ED1 waters were found to have characteristics of SACW. Likewise, adjacent waters were found to have the properties of STMW. The lines of equal density ( $\rho$, expressed here as $\sigma_{\mathrm{T}}=[\rho-1000] \mathrm{kg} \mathrm{m}^{-3}$ ) at the $T, S$ diagram also show that surface waters sampled by the thermosalinographer inside ED1 are density uniform, although $T$ and $S$ can vary at the surface within the structure. $\sigma_{\mathrm{T}}$ is about $25.5 \mathrm{~kg} \mathrm{~m}^{-3}$ inside ED1 while the values can reach over $27 \mathrm{~kg} \mathrm{~m}^{-3}$ at adjacent waters.

Table 3

Comparison of the monthly mean translational velocities found for ED1 from the visual interpretation and the MCC method

\begin{tabular}{|c|c|c|c|c|c|c|c|}
\hline \multirow[t]{2}{*}{ Month } & \multicolumn{2}{|c|}{ Visual interpretation } & \multicolumn{4}{|l|}{ MCC method } & \multirow{2}{*}{$\begin{array}{l}\text { Difference } \\
\left(\mathrm{km} \mathrm{day}^{-1}\right)\end{array}$} \\
\hline & $\begin{array}{l}\text { Speed (mean; } \\
\mathrm{km} \mathrm{day}^{-1} \text { ) }\end{array}$ & $\begin{array}{l}\text { Direction } \\
\text { (mean;deg) }\end{array}$ & $\begin{array}{l}\text { Speed (mean; } \\
\mathrm{km} \mathrm{day}^{-1} \text { ) }\end{array}$ & $\begin{array}{l}\text { Direction } \\
\text { (mean; deg) }\end{array}$ & $\begin{array}{l}\text { Speed (S.D.; } \\
\mathrm{km} \mathrm{day}^{-1} \text { ) }\end{array}$ & $\begin{array}{l}\text { Direction } \\
\text { (S.D.; deg) }\end{array}$ & \\
\hline September & 13.0 & 226 & 5.2 & 243 & 1.6 & 31 & 7.8 \\
\hline October & 6.4 & 258 & 6.0 & 222 & 2.8 & 68 & 0.4 \\
\hline November & 3.9 & 260 & 6.2 & 273 & 2.4 & 52 & 2.3 \\
\hline Mean & 7.8 & 248 & 5.8 & 246 & 2.3 & 50 & 2.0 \\
\hline S.D. & 4.7 & 19 & 0.5 & 26 & 0.6 & 18 & - \\
\hline
\end{tabular}



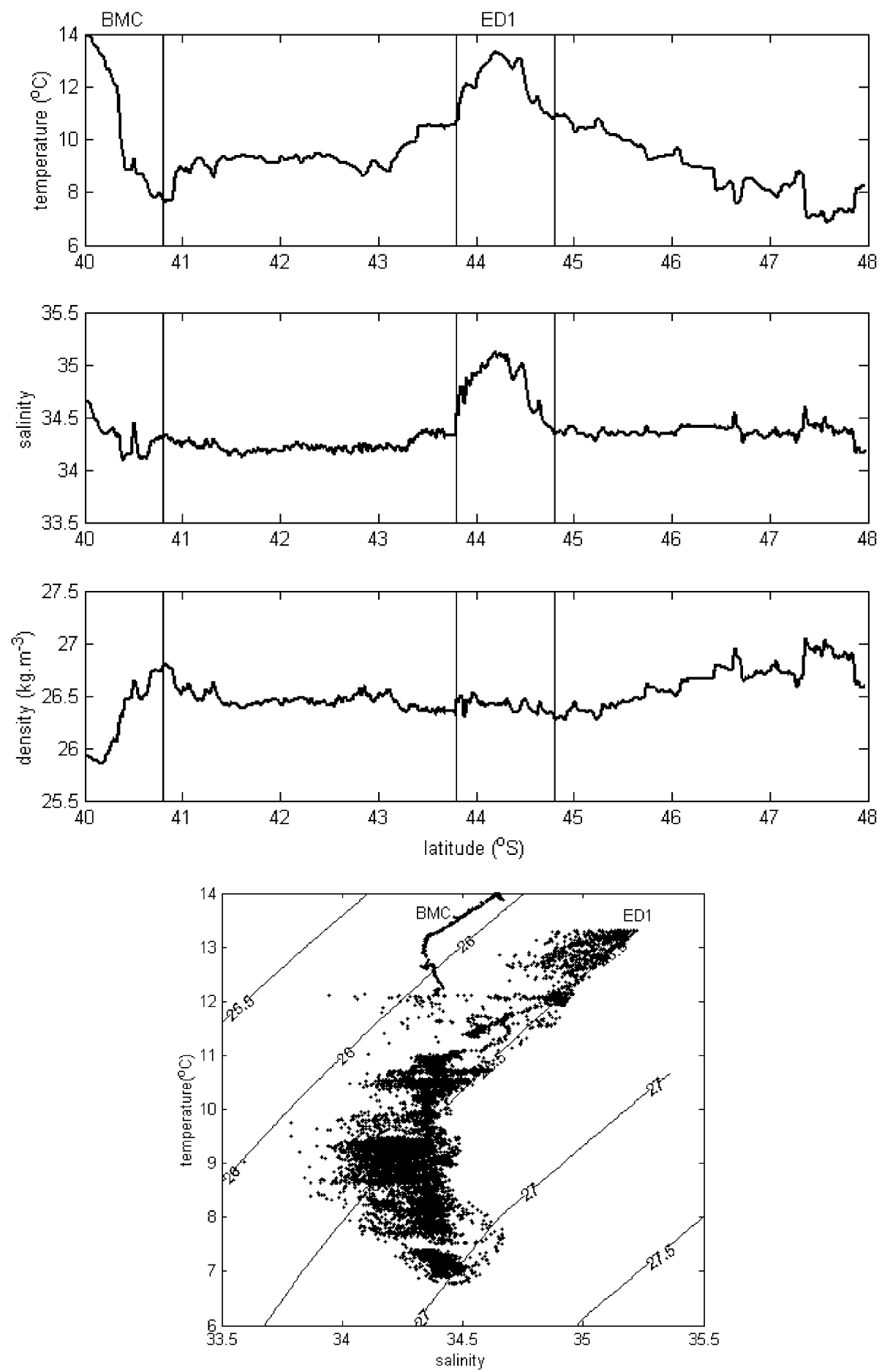

Fig. 8. Top: Temperature, salinity and density $\left(\sigma_{\mathrm{T}}\right)$ profiles taken at the surface along the ship track in $13-14$ November 2002 for the latitudes between $40^{\circ} \mathrm{S}$ and $48^{\circ} \mathrm{S}$. Bottom: $T, S$ diagram of the same data. Data have been filtered for better visualization. Eddy ED1 and the BMC front are indicated.

Gordon (1989) investigated the characteristics of the BMC region during October 1984 reporting the presence of one cold and two warm core mesoscale eddies in the region. Location and $T, S$ characteristics of ED1 are very similar to those of warm core eddy "Anthony" described by Gordon (1989). Eddy "Anthony" was reported to have carried Subtropical Water (same as SACW) and was supposed to have been in the BMC region for approximately 2.5 months before in situ measurements were taken. Since Gordon (1989) did not describe the lifecycle of eddy "Anthony", his eddy age supposition was based upon cooling rate estimates for the region.

Thermosalinograph data also reveal that the temperature (salinity) gradient between ED1 core and adjacent waters was about $0.06{ }^{\circ} \mathrm{C} \mathrm{km}^{-1}\left(0.02 \mathrm{PSU} \mathrm{km}{ }^{-1}\right)$. The temperature (salinity) gradient between $\mathrm{BC}$ and $\mathrm{MC}$ waters at the $\mathrm{BC} / \mathrm{MC}$ front was about $0.07{ }^{\circ} \mathrm{C} \mathrm{km}^{-1}$ (0.02 PSU km ${ }^{-1}$ ). Souza (2000) has investigated the nature of thermal gradients in the $\mathrm{BMC}$ 


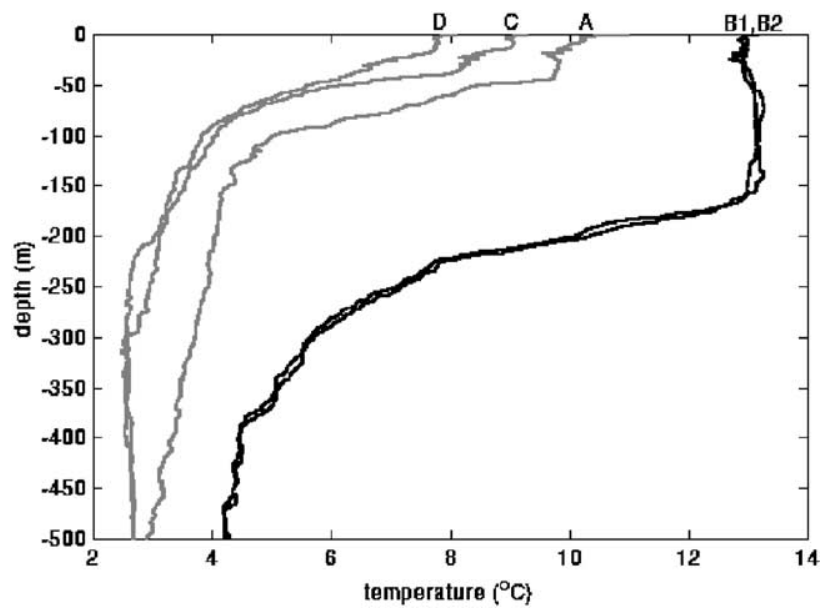

Fig. 9. XBT profiles taken in 13-14 November 2002 (A, B1, B2, C; north to south, respectively, inside eddy ED1) and in 16 November 2002 (D, south of eddy ED1).

region during 1993 and 1994 using infrared satellite images. The thermal gradients found here across the BMC front and between ED1 core and adjacent waters are in close agreement with the numbers presented by Souza (2000). Our findings also compare well with numbers presented by Legeckis (1978) and Legeckis and Gordon (1982).

Fig. 9 shows the temperature-depth profiles measured by the 5 XBT probes deployed inside and in the vicinity of ED1. The temperature inside ED1 can be considered uniform (isothermal) from the surface to the bottom of the mixed layer (located just above the thermocline at $\sim 150 \mathrm{~m}$ ). Consistently with Defant's (1961) classical theory for warm core eddies, Fig. 9 also indicates that the depth of the thermocline deepens inside ED1 in relation to adjacent waters. The $150 \mathrm{~m}$ depth at the center of ED1 is considered to be the bottom limit of the eddy on 13 November 2002. This depth is consistent with estimates made by Gordon (1989) for his eddy "Anthony".

\subsection{Eddy property change}

Fig. 7 (left panel) presents the evolution of ED1 geometry as a result of visual interpretation. Eddy geometry varies from circles to zonally orientated ellipses. Mean diameters were 111 $\mathrm{km}$ and $106 \mathrm{~km}$ for the major and minor axis, respectively. The minimum diameter found for both axes was $75 \mathrm{~km}$ while the maximum diameters were $150 \mathrm{~km}$ and $125 \mathrm{~km}$ for the minor and major axes, respectively. Standard deviations for both axes were about $20 \mathrm{~km}$. The diameters observed in ED1 are consistent with descriptions of similar warm core structures previously analyzed for the BMC region by Garzoli (1993), Legeckis and Gordon (1982), Lentini et al. (2002), Olson et al. (1988), Souza (2000), among others. ED1 diameter is about double the Rossby internal radius of deformation ( $\mathrm{Rd})$ computed by Souza (2000) for the region. This property gives a length scale at which the rotational forces (Coriolis) become comparable to the buoyancy forces (pressure gradient) in the equation of motion. Eddies with diameters larger than $\mathrm{Rd}$ are considered geostrophically balanced.
Fig. 10 shows the SST, SCC and SLA time series recorded at the center of ED1 throughout its lifespan. The mean SST observed in ED1 was $12.6{ }^{\circ} \mathrm{C}\left( \pm 0.37^{\circ} \mathrm{C}\right.$ S.D. $)$. The SST series present small amplitude oscillations that are within the accuracy of the AMSR-E SST estimation (Wentz et al., 2003). Mean (S.D.) SCC and SLA were $0.34 \mathrm{mg} \mathrm{m}^{-3}( \pm 0.06$ $\left.\mathrm{mg} \mathrm{m}^{-3}\right)$ and $0.24 \mathrm{~m}( \pm 0.07 \mathrm{~m})$, respectively. The SCC standard deviation is at the same order of magnitude of the SCC deviations presented at the center of ED1 in 18 November 2002 (Fig. 3). Variations at the SCC values throughout ED1 life span at the center of the feature can be either related to real biological activity (phytoplancton population dynamics) or to methodological restrictions when selecting the eddy's center pixel in the MODIS weekly averaged images. When reassimilation is close to happen just before day 64, eddy properties tend to change in response to the interaction with the mother current.

Lentini et al. (2002) reported that only a small fraction of the $\mathrm{BC}$ warm core eddies spawned from the retroflection area are reabsorbed back into the $\mathrm{BC}$ main current. Those authors noted only 7 eddies out of 43 had been re-assimilated by the BC. They acknowledged that the processes governing the fate of both dissipating and reabsorbed eddies are relatively still unknown for the BMC region. In contrast, the process of eddy re-assimilation is well described for other western
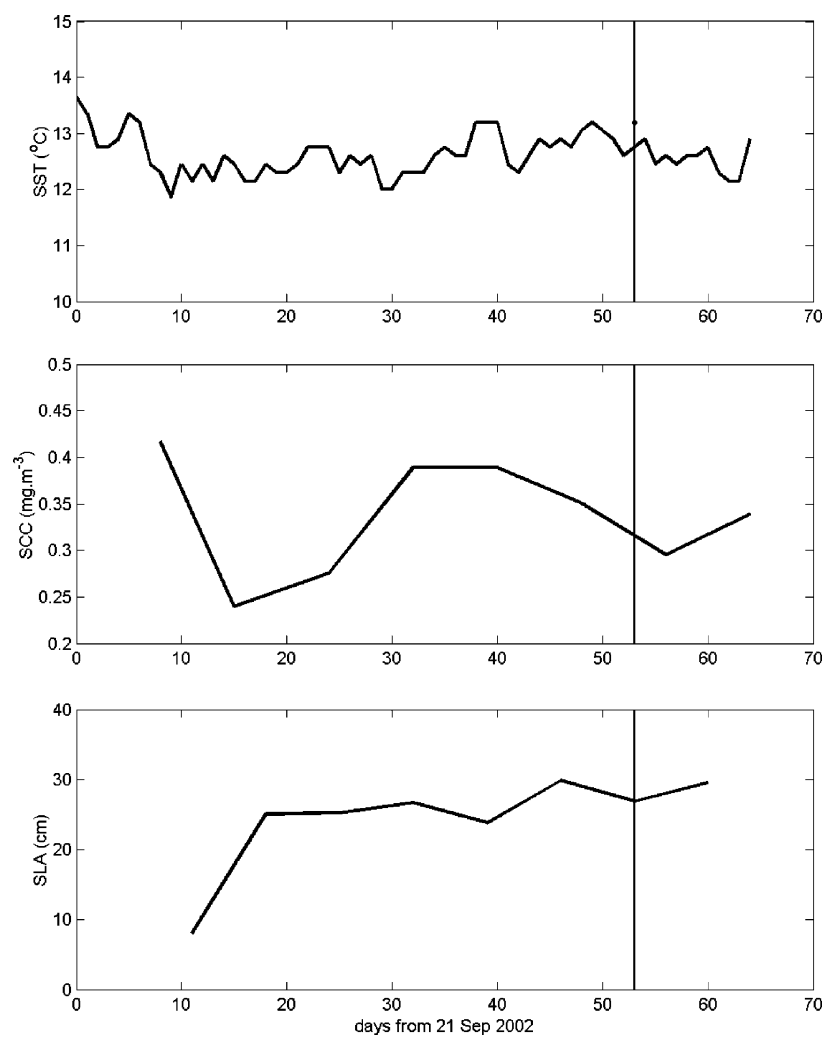

Fig. 10. Time series of SST (upper panel), SCC (middle panel) and SLA (lower panel) inside eddy ED1 during its lifetime as derived from the AMSR-E, MODIS and altimetry data, respectively. The black circle at the vertical line on day 53 (13 November 2002) represents the SST measured in situ by the thermosalinographer. 
boundary currents like the Gulf Stream (e.g. Brown et al., 1986) and the EAC.

Cresswell (1983), for instance, made a comprehensive study of eddies associated with the EAC using infrared images and in situ ship and drifting buoys data. The author observed some of the complexities of the system, like the coalescence of two eddies. In this case, a newly formed eddy had migrated northward back to the main current. Using altimetry data, Mata (2000) further observed the re-assimilation of eddies (described by their SLAs) into the main poleward flow of the EAC north of their separation latitude. The mechanisms of re-assimilation of eddies by the EAC and the $\mathrm{BC}$ seem to be similar, although less frequent in the last case as described in Lentini et al. (2002).

\subsection{Eddy volume, salt anomaly, heat content and available potential energy}

AMSR-E diameter measurements were combined with XBT depth observations of ED1 to compute ED1 volume (Vol) as previously described in Section 2.6. The mean radius (rd) was calculated as half the mean diameter or $54 \mathrm{~km}$. Taking a depth of $150 \mathrm{~m}$ to be the bottom of the eddy, ED1 had a cylindrical volume of $1.37 \times 10^{12} \mathrm{~m}^{3}$. The associated salt anomaly for this volume was $1.37 \times 10^{12} \mathrm{~kg}$. Gordon (1989) reports that warm core eddies spun off from the $\mathrm{BC}$ towards the south generally do not re-coalesce with the main thermocline as eddies do in the Gulf Stream. In the case where eddies mix into the SAMW, the structures can be important to the salt balance of the subAntarctic zone; an area known for its excess of precipitation over evaporation (Baumgartner \& Reichel, 1975). Gordon (1989) had estimated that his eddy "Asp" (circular shape, 100 $\mathrm{km}$ radius, and $400 \mathrm{~m}$ deep with 0.7 PSU anomaly) would deliver $9.034 \times 10^{12} \mathrm{~kg}$ of excess salt to the sub-Antarctic region. Our estimate for ED1 is consistent with the results from Gordon (1989).

The heat content $(\mathrm{Hc})$ of ED1 was computed to be $\mathrm{Hc}=1.78 \times 10^{19} \mathrm{cal}$ or $\mathrm{Hc}=4.24 \times 10^{18} \mathrm{~J}$. For the calculation of $\mathrm{Hc}$, the following values were used: $\rho=1026 \mathrm{~kg} \mathrm{~m}^{3}$ (Fig. 6), $c_{\mathrm{p}}=10^{3} \mathrm{~J} \mathrm{~kg}^{-1} \mathrm{~K}^{-1}$ and $T=12.6^{\circ} \mathrm{C}$ (see Section 2.6). Lentini et al. (2002), using the $8{ }^{\circ} \mathrm{C}$ isotherm as a limit for their eddy volume, computed a mean heat anomaly of about $1.9 \times 10^{19} \mathrm{~J}$ for an average sized eddy. Their results are similar to the one presented here for ED1. Moreover, Lentini et al. (2002) estimated an annual poleward heat flux of about $2.8 \times 10^{13}$ $\mathrm{W}$ based on an average eddy shedding rate of 7 per year. This represents $50 \%$ of the flux caused by Agulhas rings shed towards the South Atlantic Ocean from South Africa. The authors also believe that the $\mathrm{BC}$ eddies are not major contributors to the poleward heat flux in the Atlantic as the Agulhas rings. Both Gordon (1989) and Lentini et al. (2002) report that the $\mathrm{BC}$ eddies, however, can be important to the regional water mass formation and modification.

Using our new estimates about the heat content of dissipating eddies in the BMC region and combining those estimates with the number and translation of these structures for a given period of time, we can now assess accurately the total heat transport delivered by these $\mathrm{BC}$ eddies towards the sub-Antarctic region. Up to now, these estimates have not been fully available partly due to the absence of a method robust enough to track these eddies in the presence of cloudy skies and partly due to the lack of in situ observations. Accurate estimates of the heat content and transport of known dissipating eddies in the BMC region can be compared to results of eddy-resolving ocean circulation models running in the South Atlantic e.g. OCCAM (Ocean Circulation and Climate Advanced Modeling), POM (Princeton Ocean Model), MICOM (Miami Isopycnic Coordinate Ocean Model) and HYCOM (Miami's Hybrid Coordinate Ocean Model).

OCCAM runs at the National Oceanography Centre, Southampton (www.noc.soton.ac.uk/JRD/OCCAM/) while adapted codes of POM (www.aos.princeton.edu/WWWPUBLIC/ htdocs.pom/), MICOM (www.rsmas.miami.edu/groups/ micom.html) and HYCOM (hycom. rsmas.miami.edu/) are running at the Ocean Modeling Laboratory of the São Paulo University Oceanographic Institute (http://www.labmon. io.usp.br/), Brazil. For more information on these models, please refer to their respective web addresses. Statistics derived from this comparison are used for improving the performance of these models. However, since ED1 was actually reassimilated back into the $\mathrm{BC}$, most of its heat content was not released into the sub-Antarctic waters.

The estimated available potential energy (APE) of ED1 was $2.84 \times 10^{12} \mathrm{~J}$. This estimate is lower than the one presented by Garzoli and Garraffo (1989) whose APE value of $6.5 \times 10^{15} \mathrm{~J}$ is on the same order of magnitude as Gulf Stream eddies. Although the reduced gravity $\left(g^{\prime}\right)$ used in our work is the same as Garzoli and Garraffo (1989), discrepancies between the two estimates can be attributed to the fact that ED1 is smaller than these authors' structures. The eddies defined by Garzoli and Garraffo (1989) are also related to a limit imposed by the deeper $8{ }^{\circ} \mathrm{C}$ isotherm (which defines the thermocline in the region) whereas ED1 is limited at the bottom by the beginning of the thermocline below its $13.5^{\circ} \mathrm{C}$ isothermal structure. Considering that Garzoli and Garraffo's (1989) eddies volume and, consequently APE were overestimated in comparison to ED1, we believe the numbers presented here for ED1 are a conservative estimation.

\section{Concluding remarks}

This paper describes the characteristics of an eddy shed by the $\mathrm{BC}$ towards the sub-Antarctic environment at the BrazilMalvinas Confluence region. AMSR-E, MODIS and maps of sea level anomalies were used to account for eddy characteristics such as life span, dimensions, SST, SCC, SLA and translational velocities. An application of the MCC technique was tested to see how well it could automatically account for the translational velocities of eddies in the BMC region using AMSR-E image sequences. The performance of the MCC technique was satisfactory when the velocity vectors were compared to the ones computed manually by visual interpretation of the AMSR-E imagery. This result suggests that the 
technique can be used in the BMC region for automatically monitoring well-developed eddies in the area.

Lasting 64 days after shedding, the eddy studied here was later reabsorbed into its mother current, the $\mathrm{BC}$. Reabsorption is not a common fate for the $\mathrm{BC}$ eddies in the region. Transporting South Atlantic Central Water, the eddy's estimated volume of $1.37 \times 10^{12} \mathrm{~m}^{3}$ carried $1.37 \times 10^{12} \mathrm{~kg}$ of excess salt towards the sub-Antarctic environment. The heat content of the structure was estimated to be $4.24 \times 10^{18} \mathrm{~J}$. Should such a structure dissipate into the sub-Antarctic region as most $\mathrm{BC}$ eddies do, the associated salt anomaly would help balance the low salinity caused by excess precipitation in this region of the World Ocean (Baumgartner \& Reichel, 1975). In terms of energy, a similar eddy would deliver its heat to modify the water masses formed south of the BMC region.

Although we worked only with a single eddy in the BMC region, this paper provides new information about the threedimensional thermal signature of a typical warm core eddy present in this area. The AMSR-E instrument was successfully used for monitoring the surface characteristics of the eddy. AMSR-E unique characteristics of sampling the SST even over clouded seas at extra-tropical regions, such as the BMC, offer a viable option for eddy monitoring efforts there. Using a multisensor satellite remote sensing and in situ data approach, a proper monitoring scheme has been devised. With this scheme, both the number of eddies formed in the BMC region and their changing characteristics can be reasonably well assessed. For $\mathrm{BC}$ eddies, variables such as salt anomaly, heat content, and their translational velocities can be estimated. Together with estimates of eddy volume, these parameters can help us derive the energy and salt transport from the tropical to the subAntarctic environment across the BMC front. Techniques for improving the methods of observation and estimation of the BMC eddies characteristics and properties such as lifetime, advection, changes in size and/or volume, heat and salt dispersion or mixing, number of structures shed per year and others can benefit from the results presented here. The combination of observational data with outputs of eddyresolving circulation models of the $\mathrm{BMC}$ region can, in the future, be used for better accounting for the effective importance of the eddies for the across-front mixing processes occurring in the area.

\section{Acknowledgements}

Olga Sato and Yuri Resnichenko are acknowledged for their early contributions to the paper. Carlos Lentini and two anonymous reviewers provided very constructive criticisms incorporated into the final text. AMSR-E data are produced by Remote Sensing Systems and sponsored by NASA Earth Science REASoN DISCOVER Project and the AMSR-E Science Team. Data are available at www.remss.com. We also would like to thank the efforts of the officers and crew of the RV Ary Rongel. The Brazilian Navy provided the ship time and $\mathrm{XBT}$ probes used here. $\mathrm{CNPq}$ and the Brazilian Environmental Ministry provided the funds for project GOAL (55.0370/02-1) through the Brazilian Antarctic Program (ProAntar).

\section{References}

Baumgartner, A., \& Reichel, E. (1975). The world water balance. New York: Elsevier, 179 pp.

Brown, O. B., Cornillon, P. C., Emmerson, S. R., \& Carle, H. M. (1986). Gulf Stream warm rings: A statistical study of their behavior. Deep-Sea Research, 33, 1459-1473

Chelton, D. B., Schlax, M. G., Witter, D. L., \& Richman, J. G. (1990). GEOSAT altimeter observations of the surface circulation of the southern ocean. Journal of Geophysical Research, 95, 17877-17903.

CLS (2004). SSALTO/DUACS User Handbook: (M)SLA and (M)ADT NearReal Time and Delayed Time Products, CLS-DOS-NT-04.103, 50 pp.

Cresswell, G. R. (1983). Physical evolution of Tasman Sea eddy J. Australian Journal of Marine and Freshwater Research, 34, 495-513.

Defant, A. (1961). Physical Oceanography, vol. 1. London: Pergamon Press $729 \mathrm{pp}$.

Domingues, C. M., Gonçalves, G. A., Ghisolfi, R. D., \& Garcia, C. A. E. (2000). Advective surface velocities derived from sequential infrared images in the southwestern Atlantic Ocean. Remote Sensing of Environment, 73, 216-226.

Ducet, N., LeTraon, P. -Y., \& Reverdin, G. (2000). Global high resolution mapping of ocean circulation from TOPEX/Poseidon and ERS-1 and -2. Journal of Geophysical Research, 105, 19477-19498.

Emery, W. J., Thomas, A. C., Collins, M. J., Crawford, W. R., \& Mackas, D. L. (1986). An objective method for computing advective surface velocities from sequential infrared satellite images. Journal of Geophysical Research, $91,12865-12878$.

Fu, L. -L. (1996). The circulation and its variability of the South Atlantic Ocean: First results from the TOPEX/Poseidon mission. In G. Wefer, W. H. Berger, G. Siedler, \& D. J. Webb (Eds.), The South Atlantic: Present and past circulation (pp. 63-82). Berlin: Springer-Verlag.

Garcia, C. A. E., Sarma, Y. V. B., Mata, M. M., \& Garcia, V. M. T. (2004). Chlorophyll variability and eddies in the Brazil-Malvinas Confluence region. Deep-Sea Research, 51, 159-172.

Garzoli, S. (1993). Geostrophic velocity and transport variability in the BrazilMalvinas Confluence. Deep-Sea Research, 40(7), 1379-1403.

Garzoli, S., \& Garraffo, Z. (1989). Transports, frontal motions and eddies at the Brazil-Malvinas Currents Confluence. Deep-Sea Research, 36, 681-703.

Garzoli, S., \& Simionato, C. (1990). Baroclinic instabilities and forced oscillations in the Brazil/Malvinas Confluence front. Deep-Sea Research, 37(6), 1053-1074.

Goni, G., Kamholz, S., Garzoli, S., \& Olson, D. (1996). Dynamics of the Brazil-Malvinas Confluence based on inverted echo sounders and altimetry. Journal of Geophysical Research, 101(C7), 16273-16289.

Gordon, A. L. (1989). Brazil-Malvinas Confluence - 1984. Deep-Sea Research, 36(3), 359-384.

Hernandez, F., Le Traon, P. -Y., \& Morrow, R. (1995). Mapping mesoscale variability of the Azores Current using TOPEX/Poseidon and ERS-1 altimetry, together with hydrographic and Lagrangian measurements. Journal of Geophysical Research, 100, 24995-25006.

Legeckis, R. (1978). A survey of worldwide sea surface temperature fronts detected by environmental satellites. Journal of Geophysical Research, 83(C9), 4501-4522.

Legeckis, R., \& Gordon, A. L. (1982). Satellite observations of the Brazil and Falkland currents - 1975 to 1976 and 1978. Deep-Sea Research, 29, $375-401$.

Lentini, C. A. D., Campos, E. J. D., \& Podestá, G. (2000). The annual cycle of satellite derived sea surface temperature on the western South Atlantic shelf. Brazilian Journal of Oceanography, 48(2), 93-105.

Lentini, C. A. D., Olson, D. B., \& Podestá, G. (2002). Statistics of Brazil Current rings observed from AVHRR: 1993 to 1998. Geophysical Research Letters, 29(16), 58-1-58-4

Le Traon, P. -Y., \& Dibarboure, G. (1999). Mesoscale mapping capabilities of multi-satellite altimeter missions. Journal of Atmospheric and Oceanic Technology, 16, 1208-1223.

Le Traon, P. -Y., Dibarboure, G., \& Ducet, N. (2001). Use of a high-resolution model to analyze the mapping capabilities of multiple-altimeter missions. Journal of Atmospheric and Oceanic Technology, 18, 1277-1288. 
Le Traon, P. -Y., Nadal, F., \& Ducet, N. (1998). An improved mapping method of multi-satellite altimeter data. Journal of Atmospheric and Oceanic Technology, 15, 522-534.

Maamaatuaiahutapu, K., Provost, C., Andrié, C., \& Vigan, X. (1999). Origin and ages of mode waters in the Brazil-Malvinas Confluence region during austral winter 1994. Journal of Geophysical Research, 104(C9), 21051-21061.

Mata, M. M. (2000). On the mesoscale variability of the East Australian Current at subtropical latitude. PhD thesis. Flinders University of South Australia, Adelaide, $253 \mathrm{pp}$.

Millero, F. J., \& Poisson, A. (1981). International one-atmosphere equation of state of sea water. Deep-Sea Research, 28A, 625-629.

Olson, D. B. (1991). Rings in the ocean. Annual Review of Earth and Planetary Sciences, 19, 231-283.

Olson, D. B., Podestá, G. P., Evans, R. H., \& Brown, O. B. (1988). Temporal variations in the separation of Brazil and Malvinas currents. Deep-Sea Research, 35, 1971-1990.

O'Reilly J. E., \& 24 Coauthors. (2000). SeaWiFS postlaunch calibration and validation analyses: Part 3. In S. B. Hooker, \& E. R. Firestone (Eds.), NASA Tech. Memo. 2000-206892, vol. 11. (pp. 195-222) Mar del Plata, Argentina: NASA Goddard Space Flight Center.

Podestá, G. P. (1997). Utilización de datos satelitarios en investigaciones oceanográficas y pesqueras en el Océano Atlántico Sudoccidental. In E. E. Boschi (Ed.), El mar argentino y sus recursos pesqueros. Tomo, vol. 1 . (pp. 195-222) Mar del Plata, Argentina: Instituto Nacional de Investigación y Desarrollo Pesquero (INIDEP).

Podestá, G. P., Brown, O. B., \& Evans, R. H. (1991). The annual cycle of satellite-derived sea surface temperature in the southwestern Atlantic Ocean. Journal of Climate, 4, 457-467.
Provost, C., \& Le Traon, P.-Y. (1993). Spatial and temporal scales in altimetric variability in the Brazil-Malvinas Current Confluence region: Dominance of the semiannual period and large spatial scales. Journal of Geophysical Research, 98(C10), 18037-18051.

Reid, J. L., Nowlin, Jr., W. D., \& Patzerd, W. C. (1977). On the characteristics and circulation of the southwestern Atlantic Ocean. Journal of Physical Oceanography, 7, 62-91.

Reynolds, R. W., \& Smith, T. M. (1994). Improved global sea surface temperature analyses. Journal of Climate, 7, 929-948.

Richards, K. J., \& Gould, W. J. (1996). Ocean weather - eddies in the sea. In C. P. Summerhayles, \& S. A. Thorpe (Eds.), Oceanography: An illustrated guide (pp. 59-68). London: Manson Publishing Ltd.

Silveira, I. C. A. da., Flierl, G. R., \& Brown, W. S. (1999). Dynamics of separating western boundary currents. Journal of Physical Oceanography, $29,119-144$.

Souza, R.B. (2000). Satellite and Lagrangian observations of mesoscale surface processes in the southwestern Atlantic Ocean. PhD thesis. University of Southampton, Southampton, UK. 239 pp.

Souza, R. B., \& Robinson, I. S. (2004). Satellite and Lagrangian observations of the Brazilian Coastal Current. Continental Shelf Research, 24, 241-262.

Wentz, F. J., Gentemann, C., \& Ashcroft, P. (2003). On orbit calibration of AMSR-E and the retrieval of ocean products. 83rd Annual Meeting of the American Meteorological Society, 12th Conference on Satellite Meteorology and Oceanography, Long Beach, California, USA, 9-13th Feb. 2003.

Wentz, F. J., \& Meissner, T. (2000). AMSR Ocean Algorithm, Version 2, Remote Sensing Systems, Santa Rosa, CA (RSS Tech. Proposal 121599A-1). 